\title{
ENVOLVIMENTO DO SISTEMA NERVOSO CENTRAL NA CISTICERCOSE
}

\author{
ARISTIDES CHETO DE QUEIROZ* \\ ANA MARIA BLANCO MARTINEZ **
}

A cisticercose é condição já bem conhecida e que pode refletir o nivel de desenvolvimento da região, haja vista o mecanismo pelo qual o homem adquire a doença, quando da ingestão de alimentos contaminados pelos ovos da $T$. solium, se comportando como o hospedeiro intermediário no ciclo evolutivo deste parasito. Daí a alta frequência desta doença nos países subdesenvolvidos em contraste com aqueles mais desenvolvidos onde sua frequência é muito baixa ${ }^{3,5}$. A doença tem uma distribuição muito frequente na America Latina ${ }^{13}$ destacandose a alta incidência com que é encontrada no México, Perú e algumas regiões do Brasil.

Dentre as localizações do embrião nos vários tecidos do organismo destacase o comprometimento do sistema nervoso central (SNC) onde atinge maior importância pela gravidade que pode assumir, podendo determinar sintomatologia neurológica das mais variadas a depender do número e principalmente da localização do parasito. A neurocisticercose parece, portanto, representar o maior problema quando se estuda a patologia desta parasitose.

Informações sobre a ocorrência de neurocisticercose se referem frequentemente a dados clínicos e laboratoriais $5,7,11,12,13$ sendo que o estudo de casos de autópsias são pouco divulgados, o que pode dificultar uma melhor avaliação da gravidade desta neuroparasitose 1,6,12. Na Bahia existe apenas uma referência ao problema da neurocisticercose, onde o tema é discutido de maneira muito sumária 10.

$O$ presente trabalho mostra o estudo histopatológico mais amplo da neurocisticercose, bem como sua frequência em material de autópsia em um hospital geral.

\section{MATERIAL E METODOS}

Foram incluidos neste estudo 13 casos de cisticercose existentes entre 4.000 autópsias realizadas no Serviço de Anatomia Patológica do HPES no perído de 1949 a 1977. Todos estes casos haviam sido submetidos a autópsias completas com o exame macro e microscópico de todos os 6rgáos. Estes casos foram estudados nos seus aspectos

Trabalho realizado no Servico de Anatomia Patológica do Hospital Prof. Edgard Santos, Salvador: * Professor Assistente do Departamento de Anatomia Patológica e Medicina Legal da Universidade Federal da Bahia, Bolsista do Conselho Nacional de Desenvolvimento Científico e Tecnológico (CNPq); **Interna do Serviço de Anatomia Patologica do Hospital Prof. Edgard Santos, Bolsista do CNPq. 


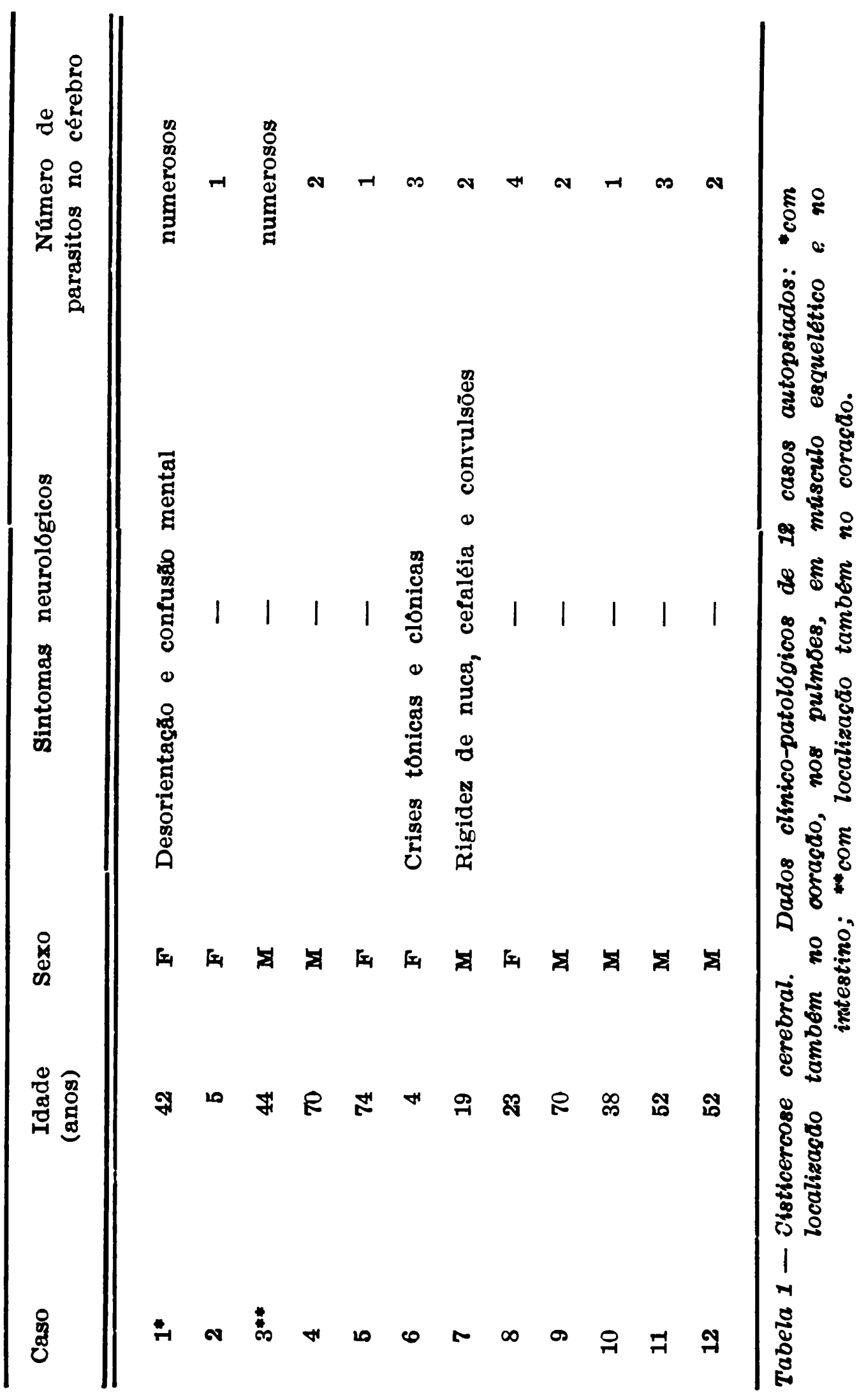


clínicos e anátomo-patológicos. Foram revistos os prontuários clínicos para obtenção de dados referentes a idade, sexo, procedência dos pacientes e existência de sintomatologia neurológica. Os protocolos de autópsias também foram revistos para verificação de aspectos macroscópicos do encéfalo e verificação de localização parasitária em outros órgăos. As láminas destes casos foram re-examinadas e novos cortes e colorações especiais além da hematoxilina e eosina foram obtidas quando necessário para melhor estudo do parasito e das reações tissulares. O estudo deste material foi feito através da técnica habitual da inclusão em parafina.

\section{RESULTADOS}

Dos 13 casos de cisticercose, encontrados em revisão de 4.000 autópsias, 12 mostravam envolvimento do SNC, numa percentagem de 0,3\%. Destes 12 casos, 10 mostravam envolvimento exclusivo encefálico. Nos demais havia também localização parasitária em outros órgãos e sistemas como coração, músculos esqueléticos, intestinos e pulmões. Um único caso não mostrou envolvimento encefálico, sendo a localização parasitária exclusiva do músculo reto-abdominal. O exame da tabela 1 mostra os principais dados clínicos e de localização parasitária encefálica destes 12 casos. No que se refere à distribuiçăo por idade observa-se apenas a maior concentraçăo de casos acima de 40 anos, mas mostra a ocorrência desde 4 a 74 anos. Sintomatologia neurológica atribuível a esta neuroparasitose foi encontrada em apenas um caso (caso 1) que corresponde ao caso do paciente com doença disseminada e com maior número de parasitos no encéfalo. Os outros dois casos em que se observou sintomas neuro-

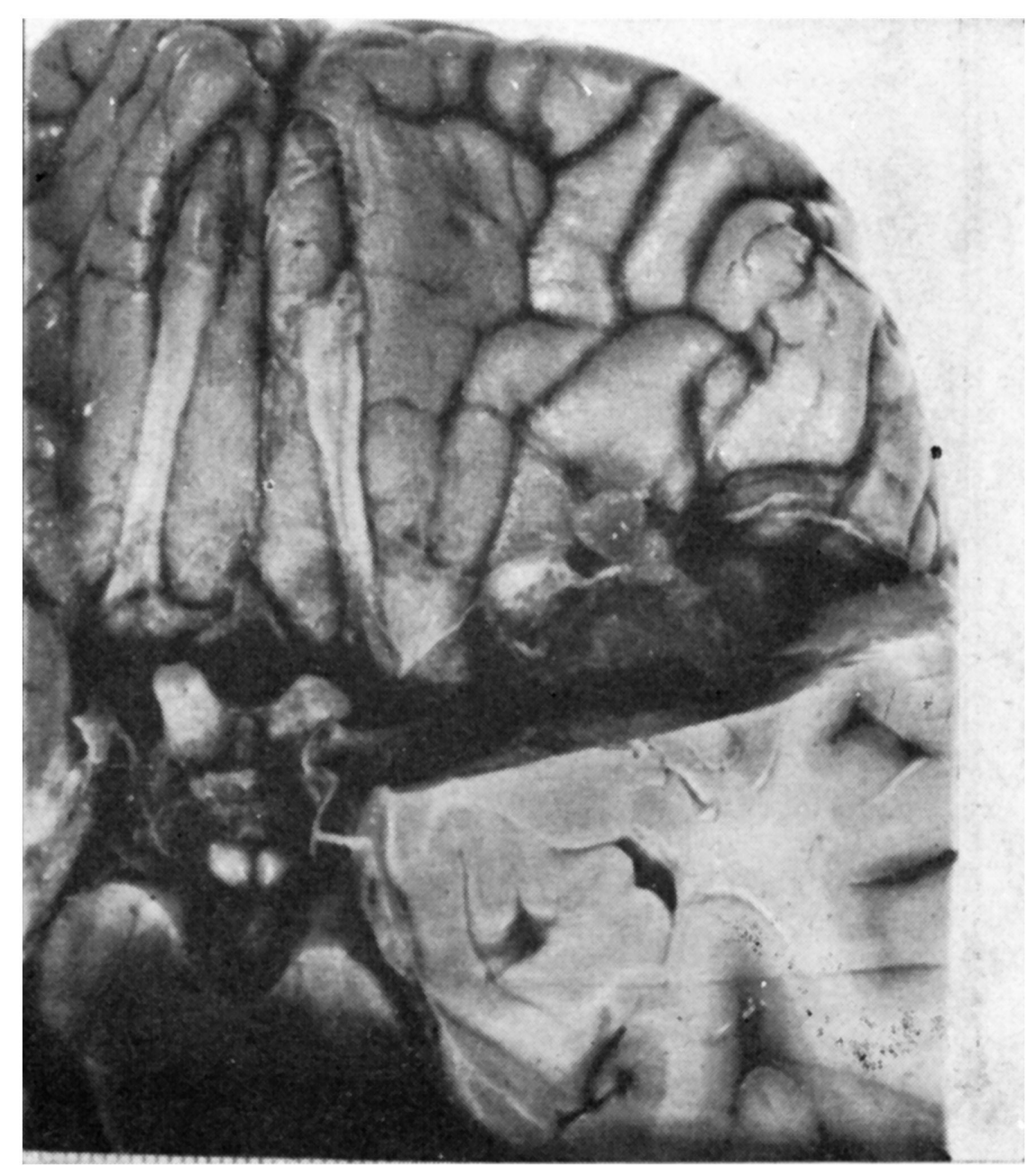

Fig. 1 - Vesicula de cisticerco aderida d meninge na regido de incisura de silvius d esquerda. 
lógicos são de pacientes com outras doenças associadas do SNC e que justificam o quadro clínico: no caso 6 o paciente, com convulsões, apresentava lesão cerebral extensa decorrente de hipoglicemia (necrose laminar da córtex); no caso 7 havia criptococose cerebral como doença básica. Nestes dois casos o envolvimento cerebral pela cisticercose foi apenas discreto com número de parasitos de 3 e 2 respectivamente. Nos demais casos os pacientes foram ao óbito em decorrência de doenças diversas.

$\mathrm{Na}$ tabela 1 eståo expressos os principais dados clínico-patológicos dos casos de neurocisticercose. Exceto nos casos 1 e 3 nos quais existiam numerosos parasitos disseminajos, em todos os outros, o número de parasitos variou entre 1 e 4 , com localização parenquimatosa, predominantemente na córtex dos lobos frontais, occipital e parietal. Na localização parenquimatosa os parasitos sempre se apresentaram como pequenas vesículas arredondadas com diametro médio de $0,5 \mathrm{~cm}$. contendo no interior pequeno nódulo esbranquiçado representando o embriăo. Apenas um caso teve localização meningea, representado por vesicula maior com $1 \times 1 \mathrm{~cm}$. irregular e semi-transparente e mostrando espessamento fibroso focal no local de aderência com a meninge (Fig. 1 ).

O estudo microscópico realizado nos 12 casos evidenciou a presença do embrião integro em 8 casos, onde foi possivel identificar a membrana envoltória do parasito com as suas três camadas características (Fig. 2). A reaçăo tissular do hospedeiro estava sempre representada por envoltório fibroso de densidade variável, acompanhada de reação celular do tipo linfo-plasmo-histiocitária, mais raramente células gigantes, e, por vezes, com quantidade variável de eosinófilos (Fig. 2). Este tipo de reaçăo foi visto tanto nos casos com localização parenquimatosa como no caso com localizaçăo meníngea. Em três casos havia nítida evidência de degeneraçăo do embriăo, mas sempre com o mesmo tipo de reação tissular descrita. Num destes casos, o embriăo

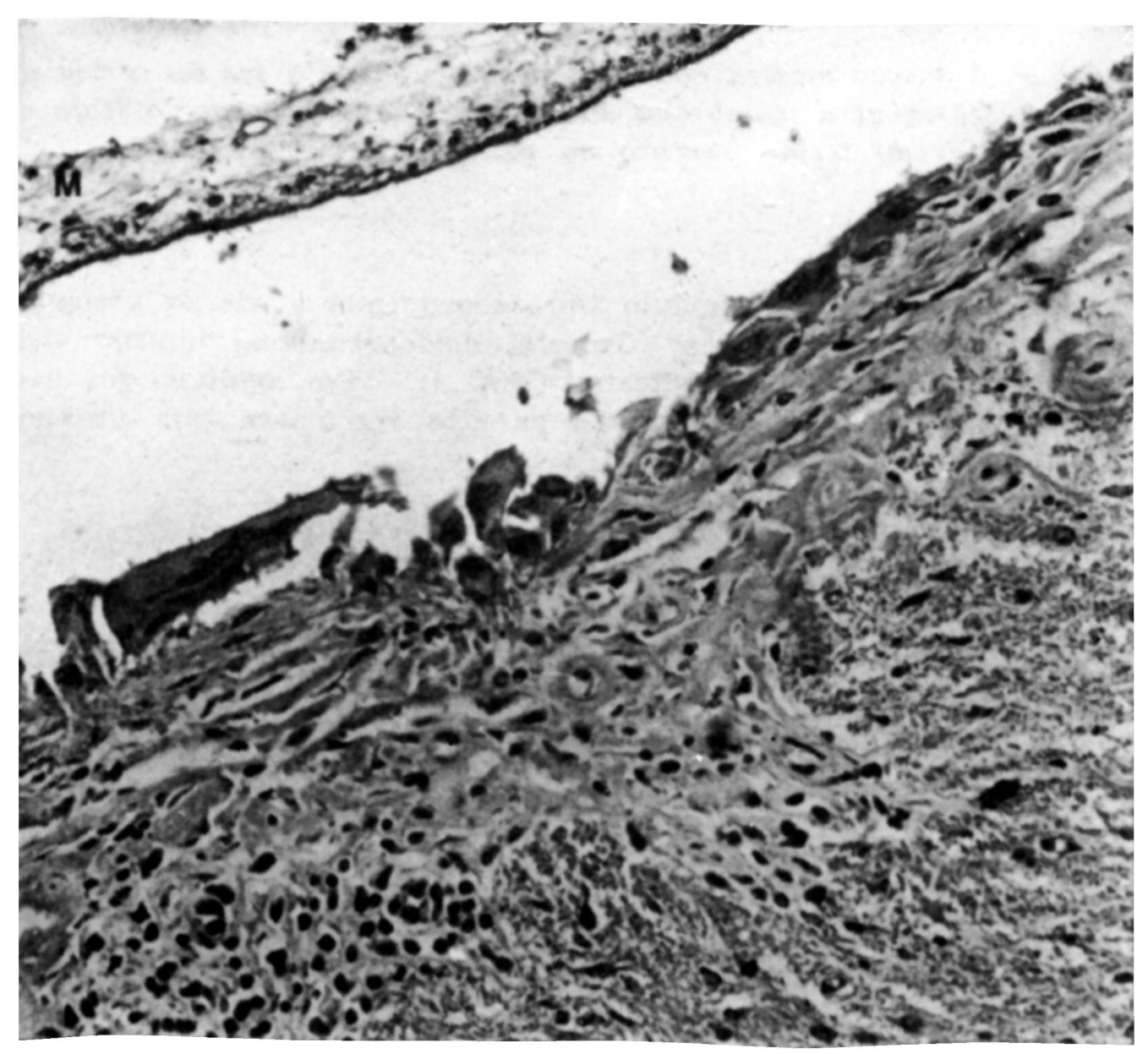

F'ig. $2-A$ seçđo mostra a reacdo fibrosante do tecido rervoso com linfocitos, histiocitos e cólulas gigantes $e$ a presenca da membrana do cisticerco (M) com suas camadas caracteristicas quitinosa, celular e areolar (H.E. 200X). 


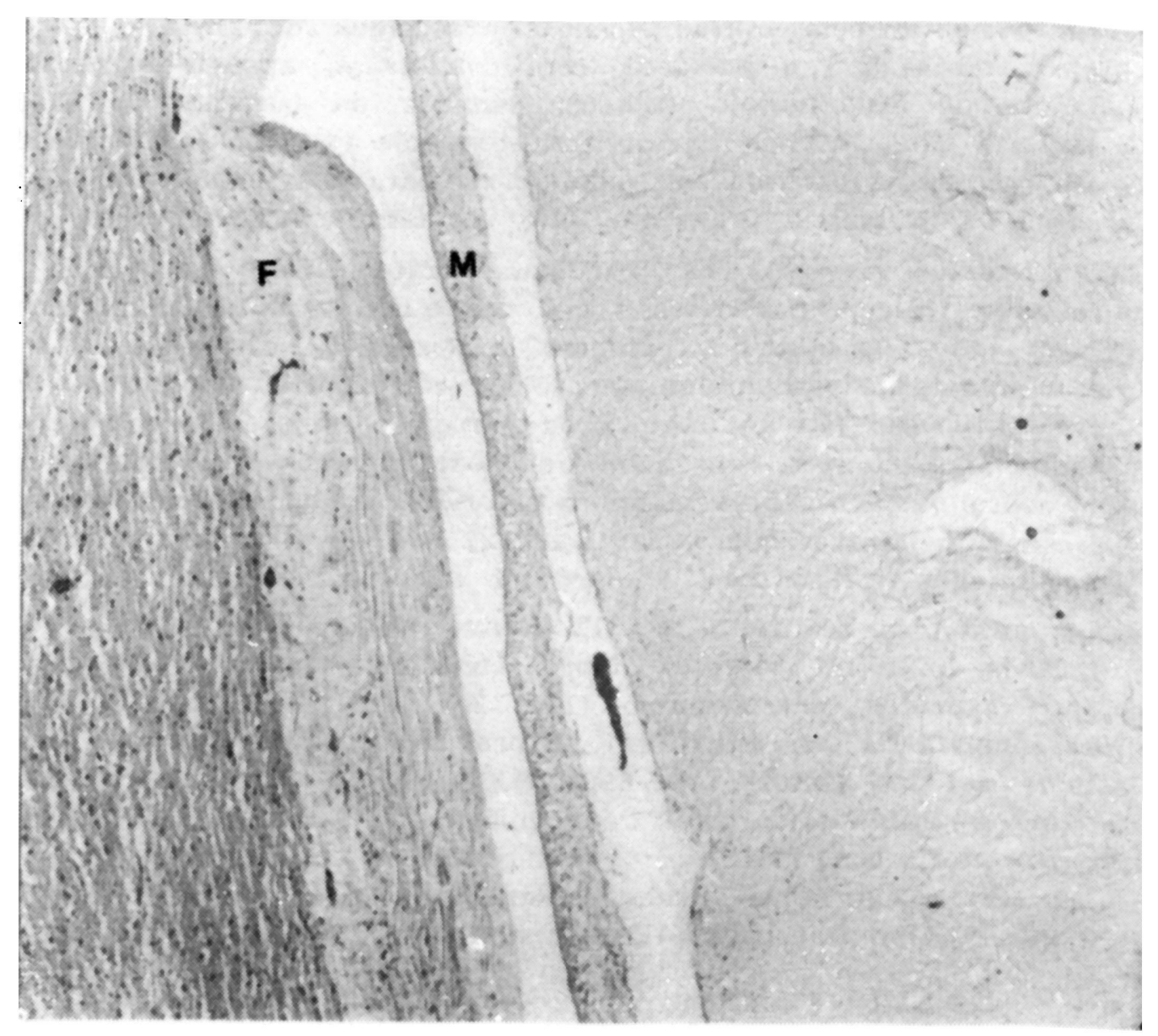

Frig. 3 - A seçđo mostra nódulo fibroso ocupando a luz da vesicula. Observar a membrana do cisticerco (M), e a reaca fibrosa do tecido nervaso ao parasito (F') (H.E. 200X).

degenerado estava substituido por nódulo fibroso ocupando a luz da vesícula (Fig. 3); neste caso a impregnação pela prata (Grocott) demonstrou no interior deste nóduln fibroso o esqueleto do embriåo do cisticerco (Fig. 4). Em nenhum dos casos examinados foi observada qualquer alteração nas paredes vasculares seja próximo ou distante da lesão.

\section{COMENTARIOS}

Exceto pelo paciente do caso número 1, que mostrava sintomatologia neurológica relacionada às alterações encefálicas determinadas pelo grande número de parasitos, a neurocisticercose apareceu sempre como achado incidental no estudo de rotina de autópsias; a frequência de $0,3 \%$ está abaixo da que é observada em outros centros $1,5,6,8,14$. A ocorrência mais frequente em indivíduos procedentes de áreas rurais demonstra mais uma vez a estreita relação entre nivel sócio-econômico e condições e condições de higiene no desenvolvimento desta parasitose.

No que diz respeito às reações do hospedeiro ao parasito, os achados aqui observados são superponíveis ao que tem sido descrito em outros trabalhos exceto pelas lesões vasculares e/ou inflamatórias distantes mencionadas por alguns autores ${ }^{14}$ mas que não foram aqui observadas. No nosso material as 


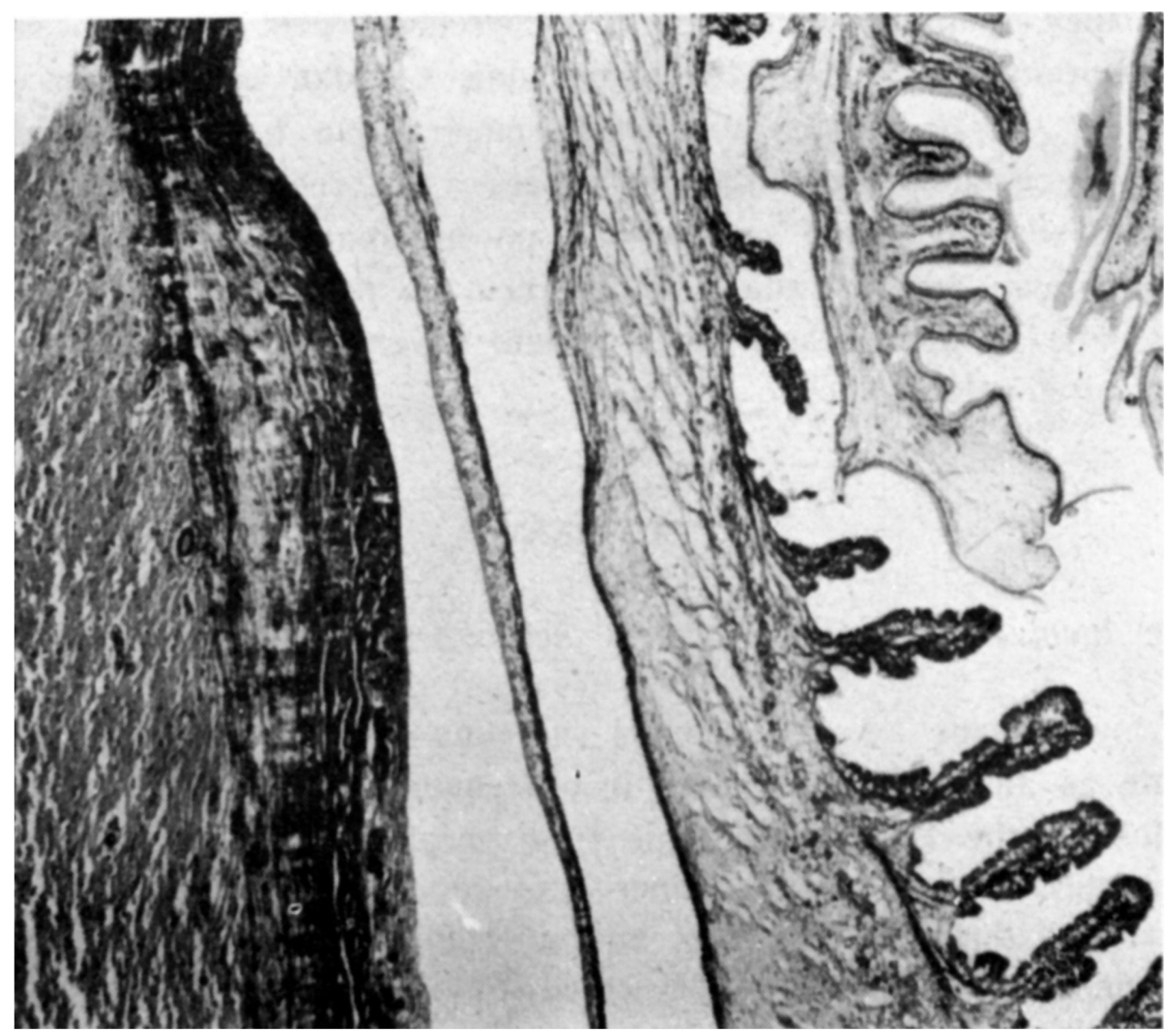

Fig. 4-A impregnacdo pela prata na mesma drea da fiyura anterior, mostrando o esqueleto do embrido do cisticerco (d direita) ressaltado no nodulo fibroso (Grocott 200X)

reações tissulares mesmo naquele caso onde havia grande disseminação de parasitos no encéfalo foram sempre localizadas, relacionadas à presença do cisticerco e representadas por lesão inflamatória crônica fibrosante. Este tipo de alteração representa uma maneira pouco usual de reação do tecido nervoso às agressões, tendo sido observada também nas lesões causadas pelos ovos de S. mansoni no sistema nervoso central ${ }^{\circ}$.

Uma observação histopatológica interessante neste estudo foi a utilização do método de impregnação pela prata (Grocott) que se mostrou de grande importância na identificação do esqueleto do embrião do cisticerco no interior das lesões cicatriciais fibróticas. Observação semelhante havia sido feita anteriormente quando do estudo de uma lesão calcificada cerebral, onde se demonstrou por este método a presença do cisticerco no interior da lesão.

Este trabalho dá, portanto, uma idéia da ocorrência da neurocisticercose na Bahia, mostrando que com esta frequência a parasitose não representa grande problema nesta área.

\section{RESUMO}

No estudo do envolvimento do SNC na cisticercose, verificou-se uma frequência de $0,3 \%$, sempre como achado incidental no estudo de rotina de 
autópsias; apenas um caso mostrou boa correlação com a presença de manifestações neurológicas. Esta frequência que é baixa em relação ao que é observado em outras regiões do Brasil, mostra que a neurocisticercose não representa um grande problema na região. As reações do hospedeiru ao embrião do cisticerco foram sempre do tipo inflamatório crônico e fibrosante. Neste estudo ficou demonstrada a importância do método de impregnação pela prata (Grocott) na identificação do esqueleto do cisticerco no interior de lesões fibrosantes e/ou calcificadas.

\section{SUMMARY}

The involvement of the central nervous system in cysticercosis.

The involvement of the central nervous system in cysticercosis was demonstrate as an incidental finding in a frequence of $0,3 \%$ in 4000 autopsied cases. Most of the 12 patients came from rural areas of the State of Bahia. The low frequence compared to other sites reported in Brasil shows that the neurcysticercosis does not represent an important problem in Bahia. The host tissue response observed was represented by a chronic fibrosing inflamatory type of reaction. This study points out the importance of the methenamine silver stain (Grocott) in the identification of the degenerated embryo inside the fibrous and/or calcified lesions.

\section{REFERENCIAS}

1. BRICENO, C. E.; BIAGI, F. \& MARTINE, B. - Cisticercose: observação sobre 97 casos de autópsia. La Prensa Med. Mex. 26:193, 1961.

2. BROTTO, W. - Aspectos neurológicos da cisticercose. Arq. Neuro-Psiquiat. (Såo Paulo) 5:258, 1947.

3. BRYANS, W. A. - Cisticercosis cerebri. Rocky Mountain Med. J. 62:57, 1965.

4. CANelas, H. M. - Cisticercose do sistema nervoso central. Rev. Med. (São Paulo) $47: 75,1963$.

5. CANeLAS, H. M. - Neurocisticercose: incidênciu, diagnóstíco e formas clínicas. Arq. Neuro-Psiquiat. (Såo Paulo) 20:1, 1962.

6. HELLMEISTER, C. R. \& FARIA, J. L. - Neurocisticercose: dados necroscópicós. Rev. Ass. Med. Brasil. 19:281, 1973.

7. MACHADO, A. S.; CAMARGO, M. E. \& HOShIMO, J. - Reaçăo de imunofluorescencia para a cisticercose com partículas de $C$. collulosas fixadas a lamina de microscopia. Rev. Soc. Bras. Med. Trop. (Săo Paulo) 7:181, 1973.

8. PEDONE, E. L. - Neurocisticercose. Rev. Ass. Med. R. G. Sul 16:133, 1972.

9. QUEIROZ, A. C. - O envolvimento do sistema nervoso central na esquistossomose mansônica. Rev. Pat. Trop. (Golás) 3:255. 1974. 
10. QUEIROZ, A. C. - O envolvimento do sistema nervoso central em algumas doeriças parasitárias. J. Brasil. Med. 30:26, 1976.

11. RIBeIro, E. B. - Cisticercose. Anais Paul. Med. Cirurg. (São Paulo) 97:324, 1970.

12. SPINA-FrANCA, A. - Cisticercose do sistema nervoso central: consideraçóes sobre 50 casos. Rev. Paul. Med. (São Paulo) 48:59, 1956.

13. SPINA-FRANÇA, A. - Imunobiologia da cisticercose: avaliação dos conceitos atuais. Arq. Neuro-Psiquiat. (Sð̊o Paulo) 27:125, 1969.

14. TRETIAKOFF, C. \& PACHECO E SILVA, A, C. - Contribuição para o estudo da cisticercose cerebral e em particular das lesóes cerebrais tóxicas à distancia nesta afeç̧ăo. Mem. Hospicio de Juquery 1:37, 1924.

Servigo de Anatomia Patologica - Hospital Prof. Edgard Santos - 40000 Salvador, $B A$ - Brasil. 